Article

\title{
A Novel and Green Method for Turning Food Waste into Environmentally-Friendly Organic Deicing Salts: Enhanced VFA Production through AnMBR
}

\author{
Qiuhong Xiang ${ }^{1}$, Kunlun Yang ${ }^{1,2,3, *}$, Ziwen Chen ${ }^{1}$, Manman Li ${ }^{1}$, Yuanqi Zhang ${ }^{1}$, Xiaorui Wang ${ }^{1}$, \\ Yingying Jiang ${ }^{1}$, Peng Gu ${ }^{1,2,3}$ and Hengfeng Miao $1,2,3,4, *$
}

1 School of Environmental and Civil Engineering, Jiangnan University, Wuxi 214122, China; 6191403017@stu.jiangnan.edu.cn (Q.X.); 6191402020@stu.jiangnan.edu.cn (Z.C.); 6191402005@stu.jiangnan.edu.cn (M.L.); 6201403007@stu.jiangnan.edu.cn (Y.Z.); 6201405088@stu.jiangnan.edu.cn (X.W.); 6181402004@stu.jiangnan.edu.cn (Y.J.); penggu@jiangnan.edu.cn (P.G.)

2 Jiangsu Key Laboratory of Anaerobic Biotechnology, Jiangnan University, Wuxi 214122, China

3 Jiangsu Engineering Laboratory of Biomass Energy and Carbon Reduction Technology, Jiangnan University, Wuxi 214122, China

4 Water Treatment Technology and Material Innovation Center, Suzhou University of Science and Technology, Suzhou 215009, China

* Correspondence: yangkunlun@jiangnan.edu.cn (K.Y.); hfmiao@jiangnan.edu.cn (H.M.); Tel.: +86-139-2115-8082 (K.Y.)

\section{check for}

updates

Citation: Xiang, Q.; Yang, K.; Chen, Z.; Li, M.; Zhang, Y.; Wang, X.; Jiang, Y.; Gu, P.; Miao, H. A Novel and Green Method for Turning Food Waste into Environmentally-Friendly Organic Deicing Salts: Enhanced VFA Production through AnMBR.

Separations 2022, 9, 11. https:// doi.org/10.3390/separations 9010011

Academic Editors: Piotr

Paweł Wieczorek and Gavino Sanna

Received: 20 November 2021

Accepted: 31 December 2021

Published: 6 January 2022

Publisher's Note: MDPI stays neutral with regard to jurisdictional claims in published maps and institutional affiliations.

Copyright: (c) 2022 by the authors Licensee MDPI, Basel, Switzerland. This article is an open access article distributed under the terms and conditions of the Creative Commons Attribution (CC BY) license (https:// creativecommons.org/licenses/by/ $4.0 /)$.

\begin{abstract}
In order to improve the production efficiency of volatile fatty acids (VFAs) by anaerobic fermentation of food waste and reduce the cost for the production of organic deicing salt (ODS), ceramic microfiltration (MF) membrane separation was applied in the conventional food waste fermenter to build an anaerobic membrane bioreactor (AnMBR). Results showed that the maximum VFA concentration in AnMBR was up to $55.37 \mathrm{~g} / \mathrm{L}$. Due to the fact that the MF membrane could realize in situ separation of VFAs, the recovery of VFAs could reach $95.0 \%$; $66.6 \%$ higher than that of traditional fermentation reactors. After the application of the MF membrane, more than $20.0 \%$ of soluble COD, $40.0 \%$ of proteins, and $50.0 \%$ of polysaccharides were retained and more than $90.0 \%$ of VFAs could be transferred in a timely fashion in the AnMBR system. In addition, the enrichment effect of the MF membrane enhanced enzymatic activities such as protease, $\alpha$-Glucosidase and acetate kinase, and increased the abundance of some important bacteria for organic acid generation such as Amphibacter, Peptoniphilus and Halomonas, which made a significant contribution to the yield of VFAs. After concentration, evaporation and crystallization, the melting efficiency of obtained ODS can reach more than $90.0 \%$ in chloride salts, which was $112.0 \%$ of commercial calcium magnesium acetate (CMA). When compared to chloride salts and CMA, ODS was more environmentally-friendly as it can reduce the corrosion of carbon steel and concrete significantly. This study created a new way of converting food waste into a high-value organic deicing agent, realizing the resource utilization of solid waste and reducing the production cost of organic deicing agents.
\end{abstract}

Keywords: food waste; deicing salt; anaerobic fermentation; AnMBR; environmentally-friendly; resource utilization

\section{Introduction}

Deicing salt is one of the main methods for the quick removal of extensive snow and ice in winter and it is widely used all over the world [1]. The most commonly-used deicing salts are sodium chloride $(\mathrm{NaCl})$ and calcium chloride $\left(\mathrm{CaCl}_{2}\right)$ as they are readily available, relatively inexpensive and efficient in melting ice and snow. However, the chemical salts of chloride deicers have caused significant economic and environmental damage by inducing the corrosion of highway structures and pavements, motor vehicles, underground cables 
and other equipment due to the strong causticity of chloride deicers [2,3]. In addition, the growth of plants and crops can be seriously affected by chloride deicers. Spraying solid deicing salt can contaminate the soil and groundwater after the melting of deicing salt [4]. Therefore, it is crucial to develop an environmentally-friendly deicing salt, which can replace the chloride deicers to alleviate the adverse impact of deicing salts on the environment.

Recently, acetate-based deicers such as calcium acetate (CA), magnesium acetate (MA), and calcium magnesium acetate (CMA) have been applied and studied as green and environmentally-friendly deicing salts [5-7]. Organic deicing salts (ODS) will not induce metal corrosion and only produce minor damage to concrete, asphalt and plants as they are non-toxic and can be converted into $\mathrm{CO}_{2}$ by biodegradation [8]. At present, ODS has been used in the U.S.A. and Canada and it is generally considered as the best road deicer to replace the environmentally unacceptable $\mathrm{NaCl}$ and $\mathrm{CaCl}_{2}$ [9]. However, the freezing point of ODS is higher than chloride deicers, resulting in a lower deicing capacity (50.0\% of traditional chloride deicers). In addition, most ODS are synthesized by chemical methods at present, such as the reaction of $\mathrm{CaCO}_{3}$ and $\mathrm{MgCO}_{3}$ from solid waste with commercial organic acids with low carbon (acetic acid) [5], which results in a high cost for the fabrication of ODS (about 10-20 times the cost of chloride salt). Consequently, the application of ODS is limited and it is mainly utilized in higher-end deicing applications for now, e.g., airport runway deicing. The high price of ODS is largely attributed to the high cost for the fabrication of the main raw material such as acetic acid, which accounts for $70.0 \%$ of the total ODS cost [10]. The cost of ODS will be significantly reduced if the fabrication cost of acetic acid can be reduced. Hence, it is urgent to search for novel and low-cost method for the fabrication of acetic acid.

At present, most of the commercial technologies for acetic acid production are accomplished through the high-cost chemical route, such as methanol carbonylation, ethanol oxidation and acetaldehyde oxidation etc. [11]. In recent years, because of wide material sources, environmental protection and low costs, biological methods concerning converting organic waste into acetic acid have attracted great interest. Food waste, consisting of a large amount of organic substances such as carbohydrates and proteins, can be used as the source for the production of biological acid. Statistics indicated that the amount of food waste reached $122 \mathrm{Mt}$ in 2018 in China. With the increasing demand for food, the amount of food waste produced in China will continue to increased [12]. Food waste easily decays and decomposes, which may cause serious environmental problems and secondary pollution if food waste is not treated properly [13]. It is a win-win strategy to use food waste as the substrate to produce volatile fatty acids (VFAs) through fermentation and the subsequent synthesize of ODS. This method can not only reduce the cost for the preparation of ODS but also realize the disposal and recycling of food waste [14].

However, according to recent studies, some key problems restrict the development and application of this technique. First, traditional fermentation systems are not efficient enough to rapidly decompose and convert certain organic substrates such as proteins and polysaccharides. The increase of VFA production is limited by the loss of these substrates and some microorganisms in the traditional anaerobic fermentation reactor [15]. Second, undissociated VFAs can permeate the cell membrane freely and inhibit the activities of microorganisms with the increasing amount of VFAs in the anaerobic fermentation system [16], and the concentration of VFAs can not be increased continuously. Hence, the generated VFAs should be separated in time. However, due to the fermentation broth being a mixture of various products including organic substrates, VFAs and fermentation microorganisms, the separation of VFAs become difficult, which leads to increasing costs for the subsequent treatment of the anaerobic fermentation process [17]. According to the latest studies, AnMBR could realize in situ separation of VFAs and the interception of substrate, which might be useful to further improve the conversion efficiency of substrate. Jomnonkhaow et al. treated cow manure with AnMBR to successfully realize the separation of VFAs and improve the yield of VFAs [18]. According to the study of Liu et al., the 
addition of a dynamic membrane in a traditional anaerobic fermentation reactor accelerated municipal sludge decomposition and made the recovery rate of VFAs reach more than 90.0\% [19]. However, the enhancement mechanism of AnMBR on the acid production from organic waste fermentation was not clear. The application of AnMBR in the food waste fermentation system for acid production is also little studied.

Hence, in order to reduce the high cost of environmentally-friendly ODS, food waste was used as a substrate in the anaerobic fermentation system to produce acetic acid in this study. A ceramic microfiltration (MF) membrane was added to the reactor to further improve the efficiency of acid production and the decomposition performance of substrates. The fermentation broth was concentrated with a forward osmosis membrane and then evaporated and crystallized to obtain the ODS. The mechanisms for AnMBR increasing the yield of VFAs was explored in this study. The obtained ODS were compared with the commercial chloride-based and acetate-based deicing salt through the evaluation of their deicing performance, metal corrosion and concrete corrosion. This novel synthesis route of environmentally-friendly ODS would realize the high-value resource utilization of food waste and contribute a new strategy for resource recycling of other organic solid wastes.

\section{Materials and Methods}

The proposed procedure is illustrated in Figure 1, which included a fermentation separation unit, a concentration unit and an evaporation crystallization unit. The fermentation separation unit was composed of a fermentation tank and a MF membrane module, whose main function was the anaerobic fermentation of food waste and the solid-liquid separation of the fermentation broth. The working volume of the fermentation tank was $4 \mathrm{~L}$, equipped with a $\mathrm{pH}$ automatic control system, a temperature control system, and an electric stirrer. The membrane module used in the AnMBR was a flat ceramic membrane (Shenzhen Huahuai New Material Co., Ltd., China) with a pore size of $50 \mathrm{~nm}$, and a total thickness of $0.40 \mathrm{~cm}$. The effective area of the membrane was $0.027 \mathrm{~m}^{2}$, the molecular weight cut-off was $100 \mathrm{KDa}$, and the main material was $\mathrm{Al}_{2} \mathrm{O}_{3}$. The fermentation broth in the reactor was pumped out by a self-priming pump. The function of the concentration unit was to concentrate the effluent of the MF membrane. The hollow fiber forward osmosis membrane module used in this study was provided by Guochu technology Co., Ltd. (Xiamen, China). The membrane was made of cellulose triacetate and possessed an asymmetric structure, a pure water flow rate of more than $27.6(\mathrm{~L} / \mathrm{h})$, a reverse salt flux less than $3 \mathrm{~g} / \mathrm{m}^{2} \cdot \mathrm{h}$, an effective area of $2.3 \mathrm{~m}^{2}$, a fiber inner diameter of $195 \mu \mathrm{m}$ and a thickness of $35 \mu \mathrm{m}$. The velocity of the draw solution for the FO was $500 \mathrm{~mL} / \mathrm{min}$. The function of the evaporative crystallization unit was to evaporate and crystallize the fermentation broth concentrated by the forward osmosis membrane.

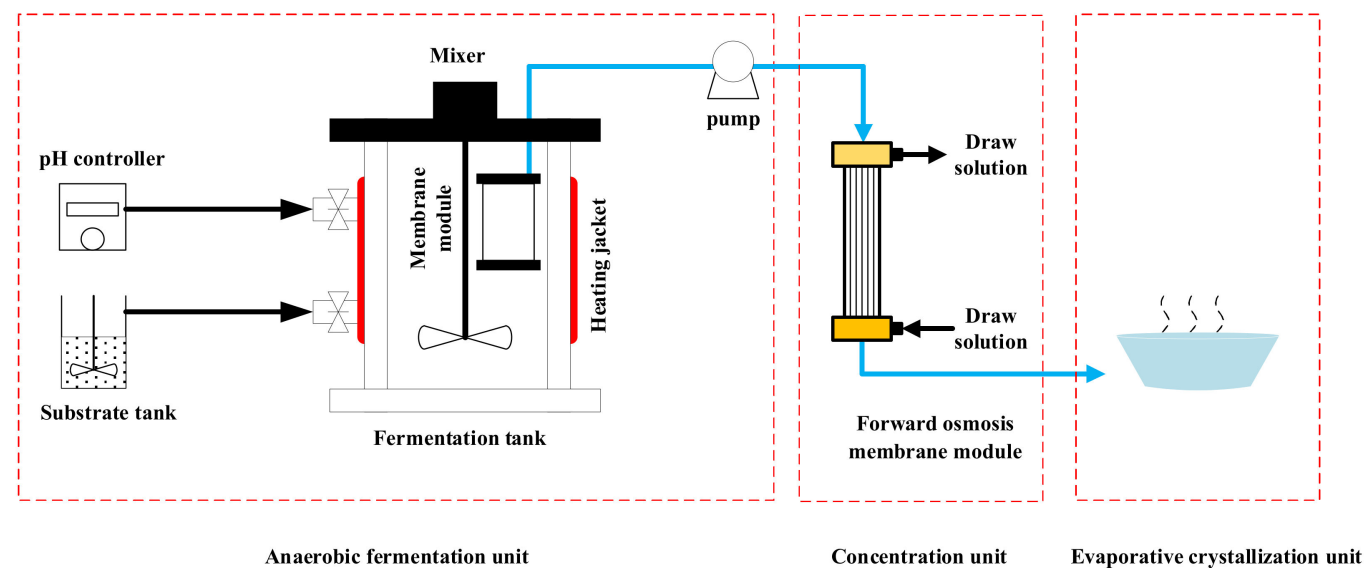

Figure 1. Schematic illustration of the novel fabrication processes for ODS. 


\subsection{Production of VFAs by Anaerobic Fermentation}

\subsubsection{Substrate and Inoculum}

The substrate used in this study was food waste slurry after the separation of solid waste and the extraction of grease, which was collected from a typical garbage power plant in Wuxi (Jiangsu Province, China). The food waste slurry was stored in a refrigerator at $4{ }^{\circ} \mathrm{C}$ and a 50-mesh screen was used to separate the large-particle residues before being pumped into the anaerobic fermentation reactor. The characterization of the food waste slurry was given in Table 1 . The main organic compounds in the food waste were polysaccharide $(51.87 \pm 3.40 \mathrm{~g} / \mathrm{L})$ and protein $(10.25 \pm 2.20 \mathrm{~g} / \mathrm{L})$. The concentrations of total chemical oxygen demand (TCOD) and total suspended solids (TSS) in the substrate were $128.0 \pm 10.00 \mathrm{~g} / \mathrm{L}$ and $27.7 \pm 2.80 \mathrm{~g} / \mathrm{L}$, respectively. The sludge obtained in the upflow anaerobic sludge bed (UASB) reactor from the same garbage power plant was used as an inoculation sludge for anaerobic fermentation.

Table 1. Characteristics of food waste slurry and sludge.

\begin{tabular}{ccc}
\hline Parameters & Food Waste Slurry & Sludge \\
\hline $\mathrm{pH}$ & $4.20 \pm 0.30$ & $7.70 \pm 0.04$ \\
$\mathrm{TSS}(\mathrm{g} / \mathrm{L})$ & $27.70 \pm 2.80$ & $12.11 \pm 1.17$ \\
VSS $(\mathrm{g} / \mathrm{L})$ & $24.20 \pm 2.17$ & $10.02 \pm 0.45$ \\
Total COD (g/L) & $128.16 \pm 10.00$ & $16 \pm 1.20$ \\
Soluble COD (g/L) & $59.33 \pm 5.80$ & $10 \pm 0.95$ \\
Protein (g/L) & $10.25 \pm 2.20$ & $/$ \\
Polysaccharide (g/L) & $51.87 \pm 3.40$ & $/$ \\
$\mathrm{TP}(\mathrm{mg} / \mathrm{L})$ & $136.75 \pm 10.75$ & $/$ \\
$\mathrm{TN}(\mathrm{mg} / \mathrm{L})$ & $1250.72 \pm 125$ & $/$ \\
$\mathrm{NH}_{4}^{+}-\mathrm{N}(\mathrm{mg} / \mathrm{L})$ & $130.73 \pm 14.70$ & $/$ \\
\hline
\end{tabular}

\subsubsection{Anaerobic Fermentation Experiment Procedure}

A batch experiment was carried out in the first 15 days to make the fermented sludge better adapted to the fermentation conditions (no analysis at this stage). Dissolved oxygen in the headspace of the reactor was removed by sparging gaseous nitrogen for approximately 30 min to maintain strictly anaerobic conditions and the temperature was maintained at approximately $35^{\circ} \mathrm{C}$. A total of $2 \mathrm{~L}$ of inoculation sludge, $1 \mathrm{~L}$ of food waste slurry and $1 \mathrm{~L}$ of deionized water were added into the reactor; the substrate and the inoculum in the reactor were fully mixed by controlling the speed of the stirrer to $120 \mathrm{rpm} / \mathrm{min}$. In stage $\mathrm{I}$, the operation parameters of temperature, $\mathrm{pH}$ and stirring intensity were the same as those in the adaptation phase. The reactor was operated in a semi-continuous mode, with the organic load being $3.2 \mathrm{~kg} \mathrm{COD} / \mathrm{m}^{3} \cdot \mathrm{d}, 100 \mathrm{~mL}$ was discharged from the reactor and $100 \mathrm{~mL}$ was fed every day. Stage I ended and stage II began when the VFAs' concentration stabilized. Indeed, stage I could be regarded as the startup phase of stage II. In stage II, the operation parameters were the same as those in stage I. A flat ceramic membrane with an average pore diameter of $50 \mathrm{~nm}$ was installed into the reactor. Then, the fermentation liquid containing VFAs and ammonia was discharged after passing through the ceramic membrane. The feeding flow rate was $7.5 \mathrm{~L} / \mathrm{m}^{2} \cdot \mathrm{h}$ and the permeate pressure was $0.2 \mathrm{bar}$ for MF. The variation of membrane flux was showed in Figure S1.

\subsection{Preparation of Organic Deicing Salt}

\subsubsection{Concentration of VFAs}

The effluent of the AnMBR was collected after the VFA production reached a stable stage, and the effluent was concentrated using the forward osmosis membrane module. A $5 \mathrm{~mol} / \mathrm{L} \mathrm{NaCl}$ solution was used as draw solution and the effluent of the AnMBR was used as feed solution. The cross-flow pattern was adopted in the concentration process, and the flow rate of the feed solution and the draw solution were controlled at $500 \mathrm{~mL} / \mathrm{min}$. When 
the osmotic pressure between the fermentation broth and the $\mathrm{NaCl}$ solution was equal, the concentration operation was be stopped.

\subsubsection{Evaporative Crystallization of Concentrated Liquid}

The fermentation broth concentrated by the forward osmosis membrane was evaporated and crystallized at $105^{\circ} \mathrm{C}$, and the obtained solid ODS was used for subsequent analysis and evaluation.

\subsection{Analytical Methods}

2.3.1. Measurements of Conventional Indices and Statistical Analysis

Conventional indices, including $\mathrm{pH}, \mathrm{NH}_{4}{ }^{+}-\mathrm{N}, \mathrm{PO}_{4}{ }^{3-} \mathrm{SS}, \mathrm{COD}$, VSS and TSS were analyzed according to the standard methods issued by the Ministry of Environmental Protection Agency of China. The concentration of soluble carbohydrates was measured by phenol-sulfuric with the reference substance of glucose as the standard [20]. The concentration of soluble protein was determined by the Lowry-Folin method with the reference substance of bovine serum albumin as the standard [21]. VFAs were measured by a gas chromatograph (GC-2010, Shimadzu, Kyoto, Japan) equipped with an automatic sample injector (AOC-20i, Shimadzu). The freezing point and melting capacity of deicing salt were determined according to the research of [22]. The determinations of protease and $\alpha$-Glucosidase (GLC) and acid-forming enzymes acetic kinase (ACK) are referred to in previous publications [23]. All tests were performed in triplicate and the average results were reported. The difference examination between some results such as enzymatic activities under different stages was assessed by using a F-test through one-way analysis of variance.

Fourier transform infrared (FT-IR) spectra of ODS were measured on a Shimadzu IRP resitge-21 spectrometer. A high-resolution X-ray diffractometer (Rigaku, D/Max Ultima III) was used to determine the crystal structure of ODS. The morphology and microstructure of ODS were observed by scanning electron microscope (SEM, Hitachi, S-4700/EX-200).

\subsubsection{Microbial Community Analysis}

The sludge samples were collected on the starting day (T0), and the 15th (T1), 30th (T2), 45th (T3), 60th (T4), 75th (T5) and 90th (T6) days for high-throughput sequencing on the Illumina MiSeq sequencing platform. OMEGA kit E.Z.N.A ${ }^{\text {TM }}$ Mag-Bind Soil DNA Kit extraction kit was used for DNA extraction. The V3-V4 regions of 16S ribosomal RNA genes were amplified using universal primers (341F-CCTACGGGNGGCWGCAG and 805R-GACTACHVGGGTATCTAATCC). For normalization of the original data obtained from the platform, each sample's sequence numbers $(\mathrm{x})$ were treated by $\log (\mathrm{x}+1)$. Then, the sequences were grouped at $90 \%$ pairwise identity after correction by Mothur [24]. The representative sequences for each operational taxonomic unit (OTU) were compared with the reference sequences from NCBI. Heatmap of the microbial community was performed by Hemi [25].

\subsubsection{Characterization of Metal Corrosion Properties}

The metal corrosion properties of the ODS and chloride deicing salt were estimated in $500 \mathrm{~mL}$ solutions with a deicing salt concentration of $5 \mathrm{wt} \%$. The weight and morphology change of metal specimens with time was studied for 4 days. The corrosion rate was calculated according to the following formula (Equation (1)) [26]:

$$
V=8760 m-m_{0} \times 10 / s \rho t
$$

where $V(\mathrm{~mm} / \mathrm{a})$ represented the corrosion rate of deicing salt to carbon steel; $m(\mathrm{~g})$ represented the loss weight of the test piece; $m_{0}(\mathrm{~g})$ represented the loss weight of pickling blank; $s\left(\mathrm{~cm}^{2}\right)$ represented the surface area of test piece; $\rho\left(\mathrm{g} / \mathrm{cm}^{3}\right)$ represented the density of test piece; $t(\mathrm{~h})$ represented the experimental time. 


\subsubsection{Salt Frost Resistance Test of Concrete}

Concrete blocks with a size of $160 \mathrm{~mm} \times 40 \mathrm{~mm} \times 40 \mathrm{~mm}$ were placed in $500 \mathrm{~mL}$ of solutions with a deicing salt concentration of $5 \mathrm{wt} \%$ and then frozen in a low-temperature incubator at $-20{ }^{\circ} \mathrm{C}$ to $-25{ }^{\circ} \mathrm{C}$ for $6 \mathrm{~h}$. After the freezing process, concrete blocks were placed at room temperature $\left(20 \pm 10^{\circ} \mathrm{C}\right)$ for $4 \mathrm{~h}$. During the experiment, the concrete block was always totally immersed in the deicing salt solution. After 25 cyclic freezing-thawing experiments, the loss weight of salt freezing for the concrete block was calculated according to the formula (Equation (2)) [26]:

$$
\Delta W n=m_{N D} / S_{N D}
$$

where $\Delta W n\left(\mathrm{~kg} / \mathrm{m}^{2}\right)$ represented the loss weight of salt freezing; $m_{N D}(\mathrm{mg})$ represented the loss weight of the test block; $S_{N D}\left(\mathrm{~mm}^{2}\right)$ represented the area of test block.

\section{Results and Discussions}

\subsection{Influence and Mechanism Analysis of AnMBR on Food Waste Fermentation}

\subsubsection{Effect of AnMBR on the VFAs' Concentration and Distribution}

It was necessary to increase the yield and output of VFAs in the anaerobic fermentation system and this was vital for improving the acetic acid production and obtaining more ODS in the subsequent process. Figure 2A showed the concentration change of total VFA in the fermentation broth with operating time. Stage I represented the conventional fermentation reactor. The main purpose of stage I was to make the fermentation system reach a stable status and obtain the maximum value of VFAs, which could also be considered as the start-up stage of stage II to some extent. In stage II, the MF membrane was added in the conventional fermentation system, leading to the possibility of the fermentation broth and the VFAs being immediately separated through the MF membrane. From the 15th to the 45th day, the total VFA concentration gradually increased from $18.20 \mathrm{~g} / \mathrm{L}$ to $33.09 \mathrm{~g} / \mathrm{L}$ and then remained stable, which indicated that the conventional fermentation system had reached stability. In stage II, the total VFA concentration was further increased when the MF membrane was installed in the reactor. From the 46th to the 90th day, the total VFA concentration gradually increased from 33.09 to $52.82 \mathrm{~g} / \mathrm{L}$ and finally stabilized at about $55.37 \mathrm{~g} / \mathrm{L}$, which was $66.6 \%$ higher than the traditional fermentation reactor. This phenomenon indicated that the yield of VFAs obtained from food waste fermentation was greatly enhanced by applying AnMBR.

Figure $2 \mathrm{~B}$ reflected the distribution change for the main components of VFAs before and after the addition of the MF membrane. In stage I, VFAs were mainly composed of acetic acid, propionic acid and n-butyric acid, which occupied an average proportion of $75.0 \%$, $9.0 \%$ and $14.0 \%$, respectively. The high proportion of acetic acid in total VFAs was the main feature of the alkaline fermentation process [27]. The proportion of other carboxylates, such as valeric acid and iso-butyric acid, were less than $2.0 \%$ in the same period. The proportion of propionic acid decreased from $21.2 \%$ to $8.4 \%$, while the proportion of n-butyric acid increased from $6.9 \%$ to $16.6 \%$ with the fermentation time. This was because of this that the carbon chain length in the primary acetic acid and propionic acid would be extended by Clostridium and other bacteria to generate butyric acid with the increased fermentation time [28]. In stage II, the main components of VFAs were still acetic acid, propionic acid and n-butyric acid. With the increased fermentation time, the proportion of acetic acid in total VFAs decreased slightly to $70.6 \%$ and the proportion of propionic acid further increased from $9.0 \%$ to $20.0 \%$. Since acetic acid with higher concentration was generated after the addition of the MF membrane, which further accelerated the process of carbon chain growth, the proportion of n-butyric acid in total VFAs of the AnMBR fermentation system was slightly higher than the conventional system. Significantly, the final concentration of acetic acid could reach $38.50 \mathrm{~g} / \mathrm{L}$ after the addition of the MF membrane, which was $50.0 \%$ higher than the conventional system and beneficial for obtaining more ODS. 


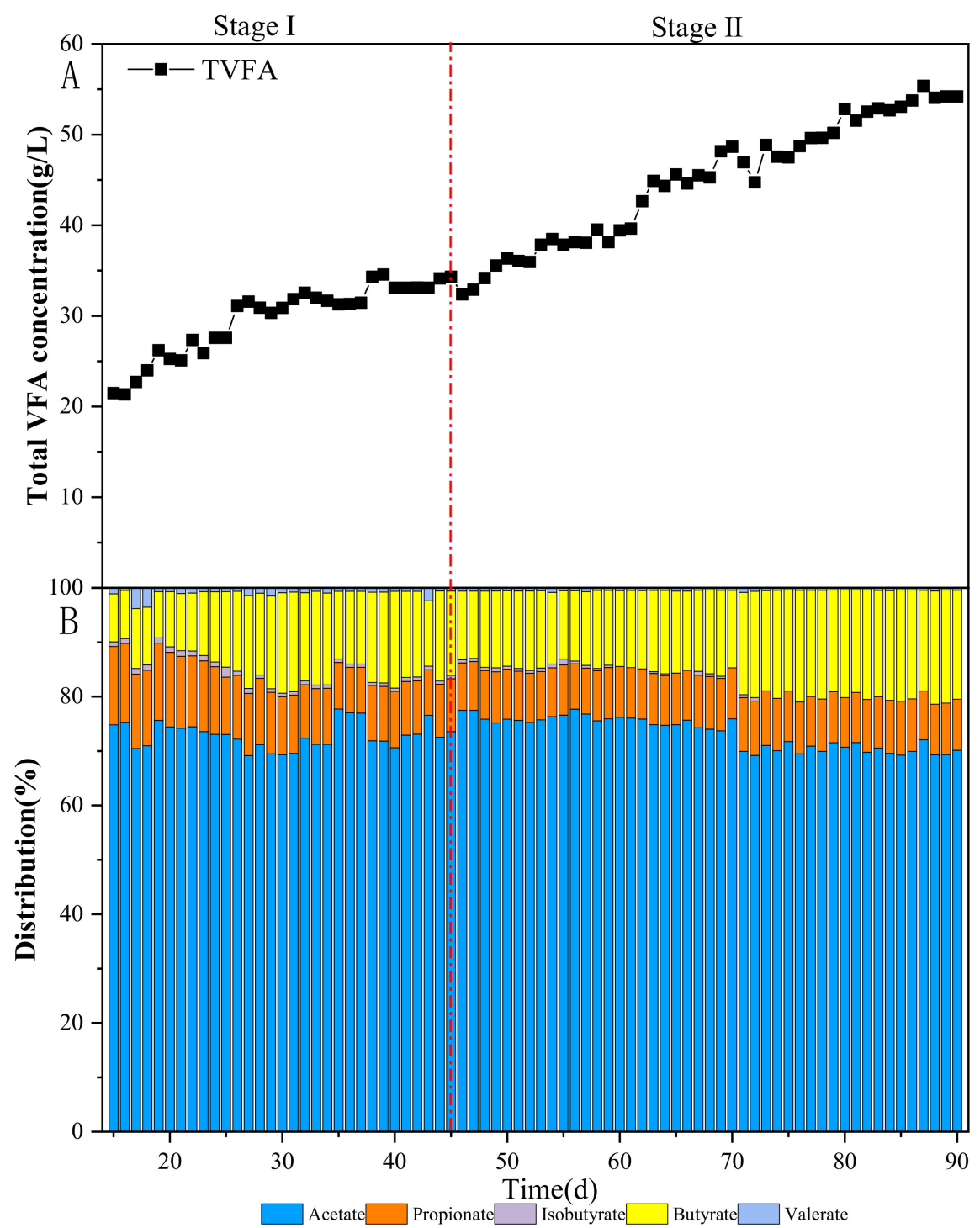

Figure 2. (A) Variations of total VFA concentration; (B) different VFAs' distribution in the system.

\subsubsection{Effect of AnMBR on Retention and Selective Diffusion}

Proteins and polysaccharides were the main components of food waste and were used as the main substrate in the anaerobic fermentation process. Figure 3A,B exhibits the concentration change of protein and polysaccharides as well as their retention efficiency in the process of stage I and stage II. In stage I, the concentrations of protein and polysaccharides in the reactor were stable and maintained at 1.61 and $0.61 \mathrm{~g} / \mathrm{L}$, respectively. The concentration of protein and polysaccharides increased rapidly when the MF membrane was added in the stage II for the reason that about $35.1 \%$ of protein and $50.2 \%$ of polysaccharides were retained in the reactor by the MF membrane. High retention efficiency of substrate by the MF membrane greatly enhanced the availability of substrate during the anaerobic fermentation process which played a key role in increasing VFA production in the AnMBR reactor [18].

Figure 3C,D reflects the retention efficiency of VFAs and soluble COD (SCOD) by the MF membrane. Since VFAs easily passed through MF membrane, the concentrations of VFAs in the effluent and the reactor was similar and their retention efficiencies were less than 5.0\%, which indicated that the generated VFAs in the AnMBR could achieve a higher recovery rate. SCOD mainly contained VFAs produced by anaerobic fermentation and other various soluble substrates, such as proteins and polysaccharides. The rejection efficiency of SCOD by the MF membrane was about $20.0 \%$. 

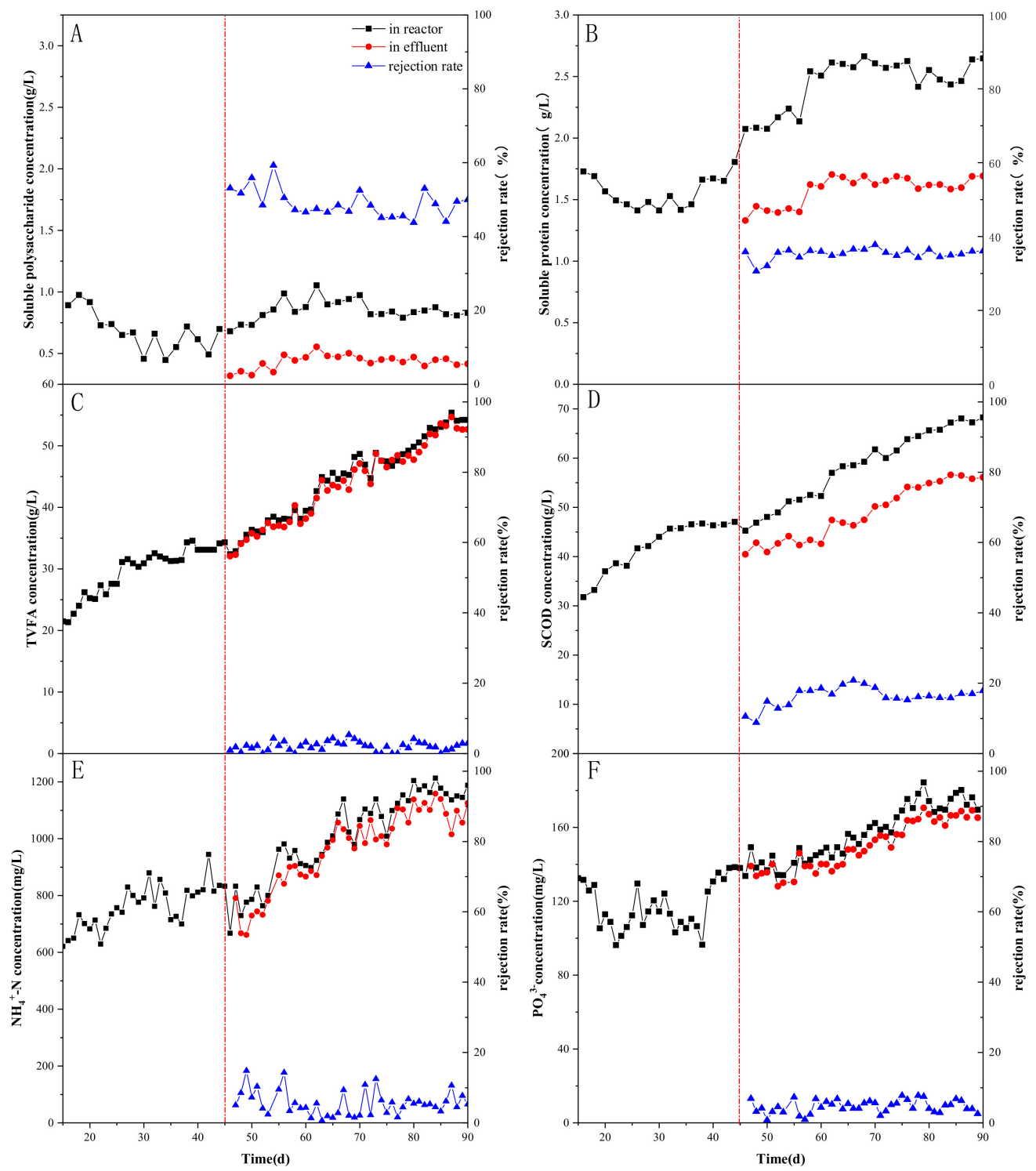

Figure 3. Variations of (A) soluble polysaccharide; (B) soluble protein; (C) VFAs; (D) soluble COD; (E) $\mathrm{NH}_{4}{ }^{+}-\mathrm{N}$, and (F) $\mathrm{PO}_{4}{ }^{3-}$ in the reactor with operation time.

The hydrolysis of organic substrates such as proteins was inevitably accompanied by the release of $\mathrm{NH}_{4}{ }^{+}$and $\mathrm{PO}_{4}{ }^{3-}$. Figure $3 \mathrm{E}, \mathrm{F}$ illustrates the concentration change of $\mathrm{NH}_{4}{ }^{+}$ and $\mathrm{PO}_{4}{ }^{3-}$ in the system during fermentation, which can reveal the degradation level of proteins. In stage I, the concentrations of $\mathrm{NH}_{4}{ }^{+}$and $\mathrm{PO}_{4}{ }^{3-}$ were about 800 and $120 \mathrm{mg} / \mathrm{L}$, respectively. When the MF membrane was added in stage II, the concentrations of $\mathrm{NH}_{4}^{+}$ and $\mathrm{PO}_{4}{ }^{3-}$ were increased to about 1200 and $160 \mathrm{mg} / \mathrm{L}$. These results indicate that the existence of the MF membrane could improve the hydrolysis efficiency of organic material such as protein. Moreover, since $\mathrm{NH}_{4}{ }^{+}$and $\mathrm{PO}_{4}{ }^{3-}$ could also easily penetrate through the MF membrane, the rejection efficiency of $\mathrm{NH}_{4}{ }^{+}$and $\mathrm{PO}_{4}{ }^{3-}$ by the MF membrane was only $10.0 \%$ [19], which indicated that $\mathrm{NH}_{4}{ }^{+}$and $\mathrm{PO}_{4}{ }^{3-}$ did not accumulate in the system. In general, a high concentration of $\mathrm{NH}_{4}{ }^{+}$might inhibit the fermentation ability of anaerobic microorganisms due to $\mathrm{NH}_{4}{ }^{+}$having a toxic effect on the anaerobic microorganisms [29]. Therefore, some products of food waste fermentation such as VFAs and ammonia were discharged in a timely manner through the MF membrane in the AnMBR, which could avoid their inhibitory effects on the fermentation ability of anaerobic microorganisms and accelerate VFA production to some extent. 


\subsubsection{Effects of the AnMBR on the Key Enzyme Activities and Microorganisms}

In order to further evaluate the effect of the MF membrane on the activity of anaerobic sludge during substrate degradation and VFA production, the activities of some typical enzymes such as proteases, $\alpha$-GLC and ACK were investigated. As shown in Figure 4, the addition of the MF membrane greatly enhanced the enzymatic activities of the sludge in the AnMBR system. In stage I, the protease activity slightly increased from $3.34 \mathrm{EU} / \mathrm{mL}$ to $4.32 \mathrm{EU} / \mathrm{mL}$. Nevertheless, the protease activity increased rapidly from $4.32 \mathrm{EU} / \mathrm{mL}$ to $6.89 \mathrm{EU} / \mathrm{mL}$ in stage II. The $\alpha$-GLC activities were very low and less than $0.1 \mathrm{EU} / \mathrm{mL}$ in stage I. Anaerobic sludge exhibited a higher $\alpha$-GLC activity of $0.2 \mathrm{EU} / \mathrm{mL}$ in stage II after the addition of the MF membrane. The high-efficient retention ability of the MF membrane for substrates in the AnMBR increased the activities of protease and $\alpha$-GLC by $60.9 \%$ and $92.2 \%$, respectively. The activity of ACK was increased from 74.9 EU/L to $122.9 \mathrm{EU} / \mathrm{L}$ after the MF was installed in the reactor. The differences between enzymatic activities in stage I and II was assessed and the results (Tables S1-S3) indicated that the significant differences among all the enzymatic activities under different stages reached a 5\% significance level. The biological enzyme mainly exists in the form of protein and could be effectively blocked by the MF membrane. Hence, efficient retention of biological enzymes by the MF membrane might make an important contribution to enhanced enzymatic activity. The accumulation of substrate for microorganisms should be another key reason for increased enzymatic activity. With the retention of the MF membrane, the substrate was accumulated in the AnMBR, which provided a rich nutrient environment for the microorganism [19]. Proteases and $\alpha$-GLC are key enzymes for the hydrolyzation of protein and carbohydrates in the hydrolysis phase. The ACK could convert Acetyl-CoA into acetic acid, which was the key enzyme for acetic acid production in anaerobic fermentation [30]. The retention of key enzymes in the hydrolytic acidification stage by the MF membrane improved the efficiency of hydrolytic acidification and further increased the yield of VFAs.
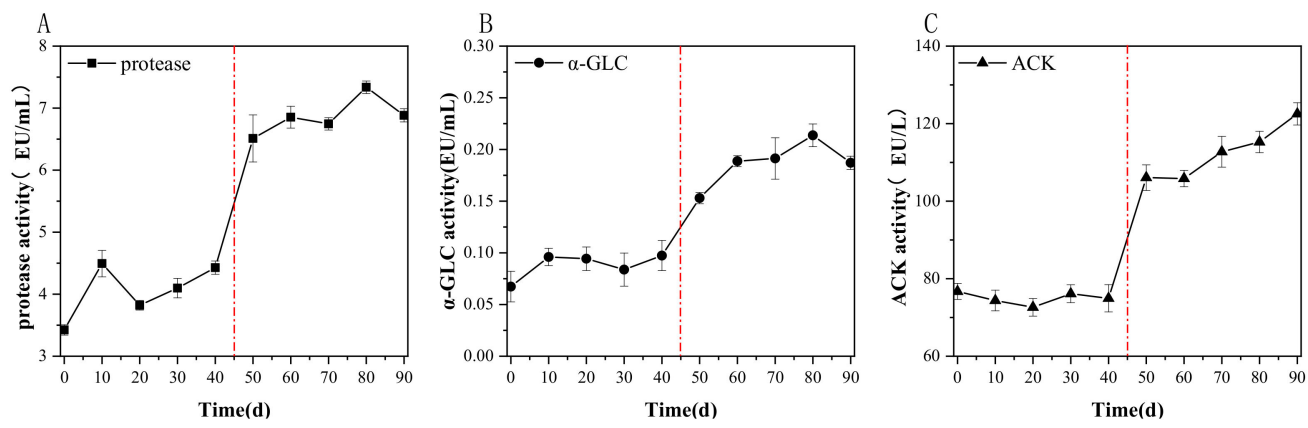

Figure 4. Influence of the MF membrane separation on enzymatic activities (A) protease; (B) $\alpha$-GLC; (C) ACK.

In order to further confirm the effect of the MF membrane on the change of functional microbial communities during substrate degradation and VFA production, a phylogenetic classification of the $16 \mathrm{~S}$ rRNA gene sequences was performed at the genus level. As shown in Figure 5, a comparative analysis revealed that the addition of the MF membrane evidently changed the bacterial communities. From stages T0 to T6, the relative abundance of some bacteria such as Lactobacillus, Tissierella and Proteinivorax increased while the activity of some other bacteria such as Romboutsia, Stenotrophomonas and Terrisporobacter was apparently suppressed. Typically, the abundance of Amphibacillus, Halomonas and Peptoniphilus increased significantly with fermentation time. These bacteria played an important role in the anaerobic fermentation process for converting organic matter into VFAs. It was noteworthy that the abundance of Amphibacillus and Halomonas further increased after the MF membrane was installed in the reactor. The genus of Amphibacillus is a facultatively anaerobic, obligately alkaliphilic and moderately alkaliphilic bacterium which is able to hydrolyze carbohydrates [31]. Halomonas can grow under alkaline conditions with high concentrations of $\mathrm{NaCl}$. Due to the gradual accumulation of salinity in the 
substrate during fermentation, the bacteria with salt tolerance were gradually selected by the surroundings and become the dominant bacteria [32]. In addition, the abundance of Peptoniphilus further increased after the installation of the MF membrane and might be involved in protein decomposition for the production of acetic acid, lactic acid and butyric acid during the degradation process of substrate [33]. Therefore, these results showed that the retention of substrates by the MF membrane also accelerated the enrichment of bacteria with special functions, which played a main role in the enhancement of the VFAs' yield from food waste anaerobic fermentation.

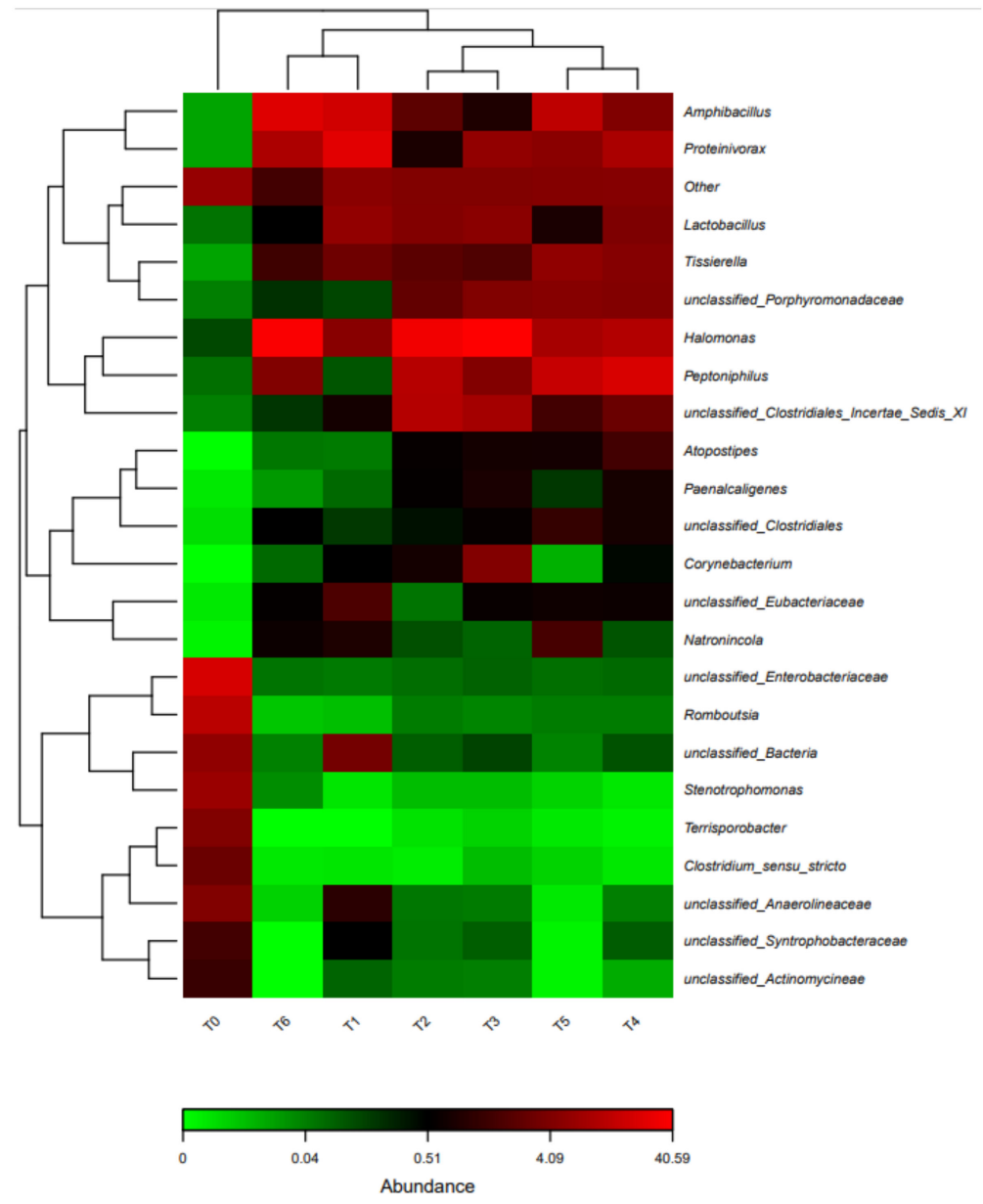

Figure 5. Bacterial community distribution at the genus level.

As a whole, the inferred mechanism of AnMBR on the increase of VFA production from food waste fermentation can be as follows: first, the interception of substrate such as protein and polysaccharide by the AnMBR improved the conversion efficiency of the substrate; second, the VFAs and ammonia could be discharged in a timely manner through the MF membrane, which avoided their inhibitory effects on the fermentation ability of anaerobic microorganisms; third, the retention by the MF membrane improved the activity of protease and $\alpha-G L C$, leading to the hydrolysis efficiency of the substrate being promoted. The activity of ACK also increased, which further promoted the conversion of acetylCoA to acetic acid. In addition, key microorganisms for acid production by anaerobic fermentation such as Amphibacter, Peptoniphilus and Halomonas were enriched, thereby improving the total production efficiency of organic acid. The greatly increased production efficiency of VFAs in the AnMBR would be better for solving the high cost of preparing environmentally-friendly deicing. 


\subsection{Preparation of Organic Deicing Salt}

The concentration of organic acid salts in the effluent of the AnMBR (stage II) was relatively low, which would waste a lot of energy if the effluent was evaporated and crystallized directly. More energy could be saved through using a forward osmosis membrane to condense the organic acid salts in the effluent. The concentration change of organic acid salts after treatment by a forward osmosis membrane is shown in Table 2. VFAs would exist in the solution with the form of organic acid salts after the addition of potassium hydroxide, which is more conducive for the subsequent concentration of salt [34]. The final concentration of organic acids reached $244.8 \mathrm{~g} / \mathrm{L}$ after concentration by the forward osmosis membrane, 4.5 times the initial concentration $(53.4 \mathrm{~g} / \mathrm{L})$. Due to the forward osmosis membrane having a high rejection efficiency of VFAs, the overall recovery of VFAs could reach $95.7 \%$. Solid ODS was then obtained through evaporation and crystallization of the fermentation liquid after concentration. The obtained ODS was characterized by FT-IR, XRD and SEM. The characterization results in the Supplementary Material (Table S4, Figures S2-S4) showed that the main components of the ODS were acetic salts. In addition, small amounts of organic substances such as proteins and polysaccharides were detected in the ODS.

Table 2. Concentration result of the forward osmosis membrane.

\begin{tabular}{ccccccc}
\hline Parameter & Acetate & Propionate & Iso-Butyrate & n-Butyrate & Valerate & VFAs \\
\hline Initial concentration (g/L) & 38.48 & 4.47 & 1.48 & 7.70 & 1.27 & 53.41 \\
Final concentration (g/L) & 175.87 & 20.67 & 6.61 & 36.36 & 5.29 & 244.80 \\
Concentration factor & 4.57 & 4.62 & 4.48 & 4.72 & 4.17 & 4.58 \\
loss VFA (g) & $/$ & $/$ & $/$ & $/$ & $/$ & 4.55 \\
Recovery rate (\%) & $/$ & $/$ & $/$ & $/$ & 95.74 \\
\hline
\end{tabular}

\subsection{Melting Performance and Environmental Impact Evaluation of ODS}

\subsubsection{Melting Ice Performance of Different Deicing Salts}

Freezing point of $\mathrm{NaCl}, \mathrm{CaCl}_{2}, \mathrm{CMA}$ and ODS were determined and compared under the same conditions. Figure 6A showed that the freezing point of all deicing agents was gradually reduced as their concentration increased from $5 \%$ to $40 \%$. When the mass fraction of all deicing agents was less than $20 \%$, the freezing point of the four deicing salts was similar. When the mass fraction was increased to $40 \%$, the freezing point of $\mathrm{CaCl}_{2}$ was the lowest, followed by ODS, $\mathrm{NaCl}$ and CMA. Apparently, the freezing point of ODS was lower than that of CMA. The relatively low freezing point of ODS provided a foundation for its application in the extreme low temperature environment.
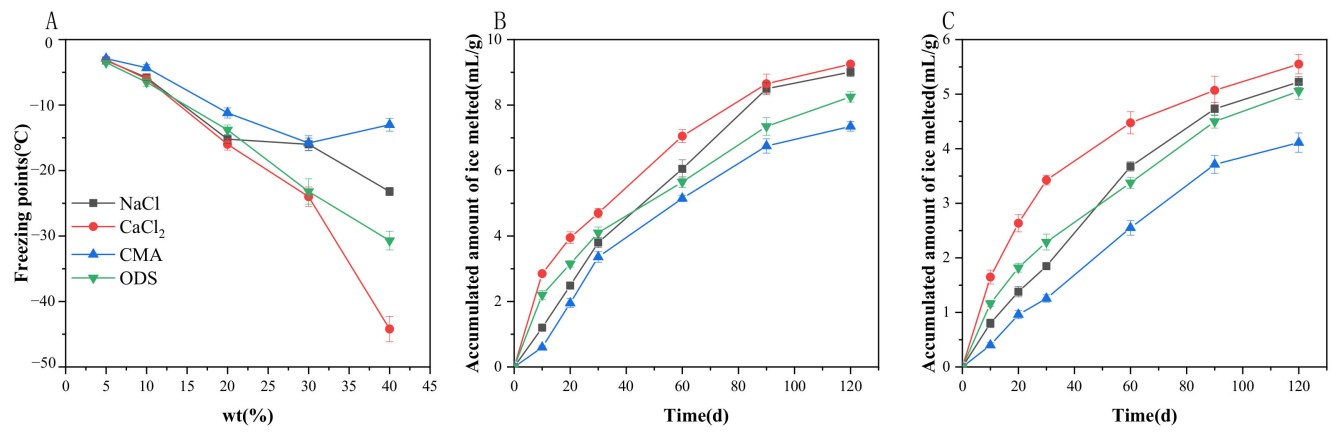

Figure 6. (A) Freezing point comparison of various deicing salts; accumulated amount of melted ice with deicing salts at $(\mathbf{B})-5^{\circ} \mathrm{C}$ and $(\mathbf{C})-15^{\circ} \mathrm{C}$.

Figure $6 \mathrm{~B}, \mathrm{C}$ presents the ice melting properties of different deicing salts at temperatures of -5 and $-15^{\circ} \mathrm{C}$. When the temperature was $-5^{\circ} \mathrm{C}$, the melting capacity of $\mathrm{CaCl}_{2}$ reached $2.85 \mathrm{~mL} / \mathrm{g}$ in the initial $10 \mathrm{~min}$ for the reason that $\mathrm{CaCl}_{2}$ could release a large amount of heat after absorbing water. Meanwhile, the deicing capacity of ODS, $\mathrm{NaCl}$, and 
CMA was $2.20 \mathrm{~mL} / \mathrm{g}, 1.2 \mathrm{~mL} / \mathrm{g}$ and $0.6 \mathrm{~mL} / \mathrm{g}$, respectively. The ODS had a strong ability to melt ice in the initial $10 \mathrm{~min}$, which might be related to its excellent water absorption ability. ODS can absorb water and dissolve to form an organic acid salt solution in a short time. After a melting time of $120 \mathrm{~min}, \mathrm{CaCl}_{2}$ had the largest melting efficiency of $9.25 \mathrm{~mL} / \mathrm{g}$, followed by $\mathrm{NaCl}$, ODS and CMA, respectively. The melting capacity of ODS was about $89.0 \%$ of $\mathrm{CaCl}_{2}, 91.0 \%$ of $\mathrm{NaCl}$ and $112.0 \%$ of $\mathrm{CMA}$. When the temperature was $-15^{\circ} \mathrm{C}$, although the melting capacity of all deicing salts was significantly reduced, the melting capacity of different deicing salts was still similar under temperatures of $-5^{\circ} \mathrm{C}$. In general, the melting capacity of ODS was significantly stronger than commercial CMA.

\subsection{Corrosion of Deicing Salts on Concrete and Carbon Steel}

The corrosion of concrete and carbon steel by different deicing salts was tested and analyzed. The results are shown in Table 3. As compared with chloride deicing salt, ODS could significantly reduce the corrosion rate of concrete and carbon steel. For example, the corrosion rate of $\mathrm{NaCl}$ and $\mathrm{CaCl}_{2}$ on carbon steel was $0.16 \mathrm{~mm} / \mathrm{a}$ and $0.19 \mathrm{~mm} / \mathrm{a}$, while the corrosion rate of CMA $(0.06 \mathrm{~mm} / \mathrm{a})$ and $\operatorname{ODS}(0.03 \mathrm{~mm} / \mathrm{a})$ on concrete was only $1 / 3$ to $1 / 6$ that of chloride deicing salt. Due to the ionic conductance of chloride ions in solution being better than organic acid ions when their concentrations are the same, the corrosion rate of chloride deicing salts is faster. In addition, chloride ions can destroy the protective oxide layer on the surface of some steels to further enhance the corrosion process [35].

Table 3. Corrosion results of concrete and carbon steel.

\begin{tabular}{ccccccc}
\hline & Parameter & $\mathbf{C K}$ & $\mathbf{N a C l}$ & $\mathbf{C a C l}_{\mathbf{2}}$ & $\mathbf{C M A}$ & ODS \\
\hline \multirow{3}{*}{ Concrete } & Initial mass of test block $(\mathrm{g})$ & 394.25 & 403.34 & 375.02 & 416.18 & 406.74 \\
& Loss mass of test block $(\mathrm{g})$ & 3.62 & 17.22 & 27.62 & 13.66 & 11.65 \\
& $\Delta W n\left(\mathrm{~kg} / \mathrm{m}^{2}\right)$ & 0.13 & 0.60 & 0.95 & 0.47 & 0.40 \\
\hline \multirow{5}{*}{ Carbon steel } & Initial mass of test piece $(\mathrm{g})$ & 24.07 & 23.94 & 24.00 & 23.87 & 24.09 \\
& Mass of test piece after & 24.03 & 23.89 & 23.94 & 23.85 & 24.08 \\
& corrosion $(\mathrm{g})$ & 0.12 & 0.16 & 0.19 & 0.06 & 0.03 \\
\hline
\end{tabular}

Figure 7A,B shows the corrosion degree of concrete with different deicing salts after 25 cyclic freeze-thaw experiments. After infiltration of the chloride deicing salt solution, the surface of the concrete became uneven. A large amount of concrete peeled off from the concrete surface and some coarse aggregates were exposed. $\mathrm{CaCl}_{2}$ showed the greatest corrosion efficiency among all deicing salts. This is because $\mathrm{Cl}^{-}$will intrude into the internal structure of concrete through capillary adsorption and internal diffusion [36], which can further exacerbate the concrete damage originating from freezing and thawing. Additionally, when concrete is immersed in the chloride deicing salt solution, the salt solution in the pores can crystallize through supersaturation to produce crystalline expansion pressure, which further destroyed the concrete [26]. However, after soaking with CMA and ODS, the surface of concrete blocks only showed a relatively small destruction and a small amount of concrete peeled off from the edges. Figure 7C,D displays the corrosion of carbon steel in various deicing agent solutions with a mass fraction of $5 \%$. The corrosion extent of the $\mathrm{NaCl}$ deicing salt on carbon steel was obvious and a lot of rust was apparent on the whole surface. As compared with $\mathrm{NaCl}, \mathrm{CaCl}_{2}$ was more corrosive and the surface of carbon steel had a black appearance, showing that the surface protection layer on the carbon steel had been damaged by $\mathrm{CaCl}_{2}$. The reason for these phenomena is that chloride ions can deteriorate the protective oxide layer on the surface of some steels, which leads to an increased corrosion rate and a faster deterioration of carbon steels. Compared with chlorine salt deicing agents, the corrosive extent of ODS on carbon steel was significantly reduced. There was only slight pitting corrosion and filiform corrosion on the surface of carbon steel after treatment with CMA deicing salt and there was no obvious corrosion on the surface of the carbon steel after the ODS treatment. The protein, carbohydrate and 
other organic matters that exist in ODS can easily be adsorbed on the surface of the steel to form a protective layer, which may have played a main role in reducing the corrosion rate and extent of ODS on carbon steel [37].
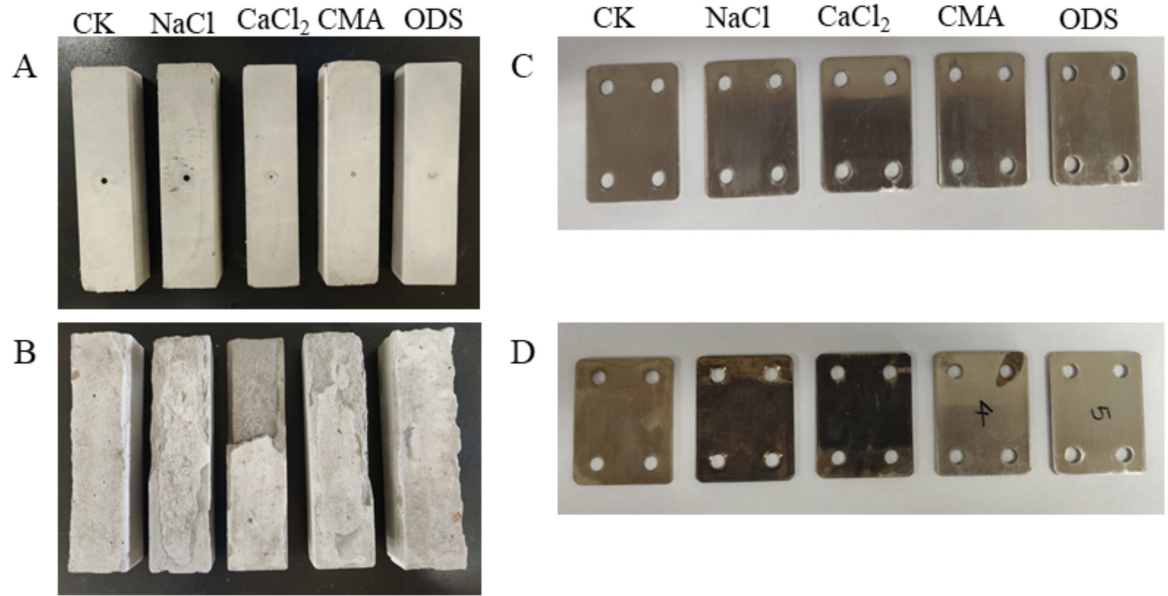

Figure 7. Corrosion of concrete (A,B) and carbon steel $(\mathbf{C}, \mathbf{D})$ with different deicing salts.

\subsection{Environmentally-Friendly Evaluation of ODS}

Traditional organic deicing salts such as CMA are synthesized from acetic acid, which accounts for $70 \%$ of the total cost. However, the problem for the high cost of acetic acid might be solved by synthesizing ODS from food waste fermentation. First, this is because that food waste belongs to municipal solid waste, which is in urgent need of treatment and has almost no extra cost. Additionally, the government would supply the corresponding subsidy for the treatment food waste at present, which further reduces the cost for the preparation of organic acid. Second, ODS prepared from food waste has a lower freezing point than commercial CMA, which makes the ice easier to melt and reduces the amount needed. In addition, ODS contains some organic matters such as carbohydrates and proteins, which can be used as corrosion inhibitors to further reduce the corrosivity of ODS. This greatly reduces the economic loss caused by the damage and corrosion of deicing salts to infrastructure. As a whole, the production of ODS from food waste and the use of ODS could not only reduce costs but also reduce maintenance costs. This new and environmentally-friendly preparation method of ODS would be beneficial to environmental protection and resource recycling.

\section{Conclusions}

In this study, a new AnMBR system was set up to increase the production and recovery efficiency of VFAs from food waste. The maximum concentrations of VFAs in AnMBR was $55.37 \mathrm{~g} / \mathrm{L}, 66.6 \%$ higher than that of a traditional fermentation reactor, and the percentage of acetic acid in total VFA could reach $70.0 \%$. Due to the application of an MF membrane, more than $20.0 \%$ of soluble COD, $40.0 \%$ of proteins and $50.0 \%$ of polysaccharides were retained and more than $90.0 \%$ of VFAs could be transferred in the AnMBR system in a timely manner. In addition, the enrichment effect of the MF membrane enhanced enzymatic activities such as protease, $\alpha$-GLC and ACK and increased the abundance of some important bacteria for organic acid generation such as Amphibacter, Peptoniphilus and Halomonas, contributing to the increasing VFA yield. The VFA concentrations in the fermentation liquid was 4.58 times higher than effluent from the AnMBR after concentration by a forward osmosis membrane, and the concentrated solution was then evaporated and crystallized to obtain solid ODS. The melting efficiency of ODS can reach more than $90.0 \%$ of chloride salts, $112.0 \%$ of commercial CMA, while the corrosion of carbon steel and concrete by ODS was obviously reduced as compared to chloride salts and CMA, proving the environmentally-friendly character of ODS. On the whole, converting food waste into a high-value organic deicing 
agent could not only realize the resource utilization of solid waste but also reduce the production cost of organic deicing agents.

Supplementary Materials: The following supporting information can be downloaded at: https: //www.mdpi.com/article/10.3390/separations9010011/s1, Figure S1: Variation of the membrane flux, Figure S2: Infrared spectrogram of product, Figure S3: XRD spectrogram of product, Figure S4: SEM images of product. Table S1: The one-way analysis of variance for protease activity under stage I and II, Table S2: The one-way analysis of variance for $\alpha$-GLC activity under stage I and II, Table S3: The one-way analysis of variance for ACK activity under stage I and II, Table S4: Ingredients in organic deicing salts.

Author Contributions: All the authors contributed to the preparation of this manuscript. Q.X. performed all the laboratory experiments and prepared the draft manuscript. K.Y. designed the framework for the experiments. Z.C., M.L., Y.Z. and Y.J. analyzed the experimental data. X.W. and P.G. helped with the manuscript preparation. H.M. conceptualized the research and corrected the manuscript. All authors have read and agreed to the published version of the manuscript.

Funding: The authors would be grateful to the National Key Research and Development Program of China (No. 2019YFC1906303), National Natural Science Foundation of China (42177376), and Wuxi Science and Technology Development Funds (No. N20201007).

Institutional Review Board Statement: Not applicable.

Informed Consent Statement: Not applicable.

Data Availability Statement: Not applicable.

Conflicts of Interest: The authors declare no conflict of interest.

\section{References}

1. Ramakrishna, D.M.; Viraraghavan, T. Environmental Impact of Chemical Deicers-A Review. Water Air Soil Pollut. 2005, 166, 49-63. [CrossRef]

2. Ganjyal, G.; Fang, Q.; Hanna, M.A. Freezing points and small-scale deicing tests for salts of levulinic acid made from grain sorghum. Bioresour. Technol. 2007, 98, 2814-2818. [CrossRef] [PubMed]

3. Ke, C.; Li, Z.; Liang, Y.; Tao, W.; Du, M. Impacts of chloride de-icing salt on bulk soils, fungi, and bacterial populations surrounding the plant rhizosphere. Appl. Soil Ecol. 2013, 72, 69-78. [CrossRef]

4. Jamshidi, A.; Goodarzi, A.R.; Razmara, P. Long-term impacts of road salt application on the groundwater contamination in urban environments. Environ. Sci. Pollut. Res. Int. 2020, 27, 30162-30177. [CrossRef]

5. Fu, W.; Mathews, A.P. Two-stage fermentation process for the production of calcium magnesium acetate and propionate road deicers. Enzym. Microb. Technol. 2005, 36, 953-959. [CrossRef]

6. Wu, Y.H. Study on Environmentally-Friendly Snow-Melting Agents Application. Adv. Mater. Res. 2013, 709, 923-927. [CrossRef]

7. Liu, Z.Q.; Jiang, F.Y.; Liu, R.C. Preparation of Environment-Friendly Deicing Salt of Calcium-Magnesium Acetate from Apple Sticks. Appl. Mech. Mater. 2012, 178, 954-957. [CrossRef]

8. Zhang, H.; Zhang, Z.; Zhao, Y.; Liu, Y. Preparation of Calcium Magnesium Acetate Snow Melting Agent Using Raw Calcium Acetate-Rich Made from Eggshells. Waste Biomass Valorizat. 2019, 11, 6757-6767. [CrossRef]

9. Kolesar, K.R.; Mattson, C.N.; Peterson, P.K.; May, N.W.; Prendergast, R.K.; Pratt, K.A. Increases in wintertime PM2.5 sodium and chloride linked to snowfall and road salt application. Atmos. Environ. 2018, 177, 195-202. [CrossRef]

10. Dionysiou, D.D.; Tsianou, M.; Botsaris, G.D. Investigation of the Conditions for the Production of Calcium Magnesium Acetate (CMA) Road Deicer in an Extractive Crystallization Process. Crystal Res. Technol. 2000, 35, 1035-1049. [CrossRef]

11. Lee, W.S.; Chua, A.S.M.; Yeoh, H.K.; Ngoh, G.C. A review of the production and applications of waste-derived volatile fatty acids. Chem. Eng. J. 2014, 235, 83-99. [CrossRef]

12. Liu, M.; Ogunmoroti, A.; Liu, W.; Li, M.; Bi, M.; Liu, W.; Cui, Z. Assessment and projection of environmental impacts of food waste treatment in China from life cycle perspectives. Sci. Total Environ. 2021, 807, 150751. [CrossRef]

13. Sharma, P.; Gaur, V.K.; Kim, S.H.; Pandey, A. Microbial strategies for bio-transforming food waste into resources. Bioresour. Technol. 2020, 299, 122580. [CrossRef]

14. Luo, J.; Huang, W.; Guo, W.; Ge, R.; Zhang, Q.; Fang, F.; Feng, Q.; Cao, J.; Wu, Y. Novel strategy to stimulate the food wastes anaerobic fermentation performance by eggshell wastes conditioning and the underlying mechanisms. Chem. Eng. J. 2020, 398, 125560. [CrossRef]

15. Liu, H.; Xiao, H.; Yin, B.; Zu, Y.; Liu, H.; Fu, B.; Ma, H. Enhanced volatile fatty acid production by a modified biological pretreatment in anaerobic fermentation of waste activated sludge. Chem. Eng. J. 2016, 284, 194-201. [CrossRef] 
16. Zhou, M.; Yan, B.; Wong, J.W.C.; Zhang, Y. Enhanced volatile fatty acids production from anaerobic fermentation of food waste: A mini-review focusing on acidogenic metabolic pathways. Bioresour. Techno.l 2018, 248, 68-78. [CrossRef]

17. Parchami, M.; Wainaina, S.; Mahboubi, A.; I'Ons, D.; Taherzadeh, M.J. MBR-Assisted VFAs Production from Excess Sewage Sludge and Food Waste Slurry for Sustainable Wastewater Treatment. Appl. Sci. 2020, 10, 2921. [CrossRef]

18. Jomnonkhaow, U.; Uwineza, C.; Mahboubi, A.; Wainaina, S.; Reungsang, A.; Taherzadeh, M.J. Membrane bioreactor-assisted volatile fatty acids production and in situ recovery from cow manure. Bioresour. Technol. 2021, 321, 124456. [CrossRef]

19. Liu, H.; Wang, Y.; Yin, B.; Zhu, Y.; Fu, B.; Liu, H. Improving volatile fatty acid yield from sludge anaerobic fermentation through self-forming dynamic membrane separation. Bioresour. Technol. 2016, 218, 92-100. [CrossRef]

20. DuBois, M.; Gilles, K.A.; Hamilton, J.K.; Rebers, P.A.; Smith, F. Colorimetric Method for Determination of Sugars and Related Substances. Anal. Chem. 2002, 28, 350-356. [CrossRef]

21. Lowry, O.; Rosebrough, N.; Farr, A.L.; Randall, R. Protein Measurement with the Folin Phenol Reagent. J. Biol. Chem. 1951, 193, 265-275. [CrossRef]

22. Chung, K.H.; Jung, S.C.; Park, B.G. Eco-friendly deicer prepared from waste oyster shells and its deicing properties with metal corrosion. Environ. Technol. 2021, 42, 3360-3368. [CrossRef]

23. Goel, R.; Mino, T.; Satoh, H.; Matsuo, T. Enzyme activities under anaerobic and aerobic conditions in activated sludge sequencing batch reactor. Water Res. 1998, 32, 2081-2088. [CrossRef]

24. Schloss, P.D.; Westcott, S.L.; Ryabin, T.; Hall, J.R.; Hartmann, M.; Hollister, E.B.; Lesniewski, R.A.; Oakley, B.B.; Parks, D.H.; Robinson, C.J.; et al. Introducing mothur: Open-source, platform-independent, community-supported software for describing and comparing microbial communities. Appl. Environ. Microbiol. 2009, 75, 7537-7541. [CrossRef] [PubMed]

25. Deng, W.; Wang, Y.; Liu, Z.; Cheng, H.; Xue, Y. HemI: A toolkit for illustrating heatmaps. PLoS ONE 2014, 9, e111988. [CrossRef] [PubMed]

26. Guo, Z.; Zhu, Q.; Liu, C.; Xing, Z. Preparation of Ca-Al-Fe deicing salt and modified with sodium methyl silicate for reducing the influence of concrete structure. Constr. Build. Mater. 2018, 172, 263-271. [CrossRef]

27. Huang, W.; Huang, W.; Yuan, T.; Zhao, Z.; Cai, W.; Zhang, Z.; Lei, Z.; Feng, C. Volatile fatty acids (VFAs) production from swine manure through short-term dry anaerobic digestion and its separation from nitrogen and phosphorus resources in the digestate. Water Res. 2016, 90, 344-353. [CrossRef] [PubMed]

28. Seedorf, H.; Fricke, W.F.; Veith, B.; Bruggemann, H.; Liesegang, H.; Strittmatter, A.; Miethke, M.; Buckel, W.; Hinderberger, J.; Li, F.; et al. The genome of Clostridium kluyveri, a strict anaerobe with unique metabolic features. Proc. Natl. Acad. Sci. USA 2008, 105, 2128-2133. [CrossRef]

29. Chen, J.L.; Ortiz, R.; Steele, T.W.; Stuckey, D.C. Toxicants inhibiting anaerobic digestion: A review. Biotechnol. Adv. 2014, 32, 1523-1534. [CrossRef]

30. Drake, H.L.; Küsel, K.; Matthies, C. Acetogenic Prokaryotes. In The Prokaryotes; Springer: Cham, Switzerland, 2006; pp. 354-420.

31. Aino, K.; Hirota, K.; Okamoto, T.; Tu, Z.; Matsuyama, H.; Yumoto, I. Microbial Communities Associated With Indigo Fermentation That Thrive in Anaerobic Alkaline Environments. Front. Microbiol. 2018, 9, 2196. [CrossRef]

32. Xiao-Ran, J.; Jin, Y.; Xiangbin, C.; Guo-Qiang, C. Halomonas and Pathway Engineering for Bioplastics Production. Methods Enzymol. 2018, 608, 309-328. [CrossRef]

33. Tomazetto, G.; Hahnke, S.; Maus, I.; Wibberg, D.; Puhler, A.; Schluter, A.; Klocke, M. Complete genome sequence of Peptoniphilus sp. strain ING2-D1G isolated from a mesophilic lab-scale completely stirred tank reactor utilizing maize silage in co-digestion with pig and cattle manure for biomethanation. J. Biotechnol. 2014, 192, 59-61. [CrossRef]

34. Blandin, G.; Rosselló, B.; Monsalvo, V.M.; Batlle-Vilanova, P.; Viñas, J.M.; Rogalla, F.; Comas, J. Volatile fatty acids concentration in real wastewater by forward osmosis. J. Membr. Sci. 2019, 575, 60-70. [CrossRef]

35. Sajid, H.U.; Kiran, R.; Qi, X.; Bajwa, D.S.; Battocchi, D. Employing corn derived products to reduce the corrosivity of pavement deicing materials. Constr. Build. Mater. 2020, 263, 120662. [CrossRef]

36. Liu, Z.; Hansen, W. Pore damage in cementitious binders caused by deicer salt frost exposure. Constr. Build. Mater. 2015, 98, 204-216. [CrossRef]

37. Raja, P.B.; Sethuraman, M.G. Natural products as corrosion inhibitor for metals in corrosive media-A review. Mater. Lett. 2008, 62, 113-116. [CrossRef] 